\title{
USING ADVENTURE TO INCREASE THE EMOTIONAL INTELLIGENCE OF THE POOR
}

\section{Roelf Reyneke}

\section{INTRODUCTION}

In many instances the clients that social workers encounter are trapped by poverty and experience feelings of powerlessness (Reyneke, 2000:384). In order to help them the social worker should use his or her skills and knowledge to assist clients to reclaim the power that they lost or possibly never possessed in the first place. Payne (2005:295) analyses empowerment and argues that clients can gain power of decision and action over their own lives by reducing the effect of social or personal blocks to exercising existing power, by increasing their personal capacity and self-confidence to use power, and by transferring power from groups and individuals. Reyneke (2000:383-384) shows that in order to empower people in poor communities more effectively, their human potential needs to be developed. This may be done through the development of their emotional intelligence (EQ). Techniques that reduce the effect of social or personal blocks should be used in order to help them improve, amongst other aspects, their personal capacity and self-confidence. This is especially important when planning and implementing sustainable development projects where many of the participants are from communities that experience powerlessness and are poor.

The purpose of this article is to redefine poverty and to demonstrate and describe how adventure programmes can be used to empower the poor so that they can experience improved adaptation to their environment and in that way become well-adjusted, well-motivated citizens. The techniques under discussion are focused on the development of EQ and employ the experiential learning theory in the form of cooperative games, problem solving, communication and trust activities, which are not very expensive and prove helpful in the fight against poverty as they provide a method for training, empowering and motivating people. These techniques are used to develop EQ that could lead to the improvement of human potential and the empowerment of individuals, groups and communities.

This is a literature study, although mention will be made of experience from personal practice. The methods and techniques under discussion have been used successfully over the last four years by the researcher and by the persons he has trained.

\section{Rethinking poverty}

Poverty can mean different things to different people. Traditionally the most important "thread" in poverty discourse has been the notion of a material lack, especially the lack of resources necessary for survival (Poverty and Inequality Institute, 2007:10). This type of poverty is not new in South Africa. In 2001 the country's unemployment rate was $29,4 \%$, but came down to 25,5\% in 2006 (Statistics South Africa, 2006:10). This statistic is indicative of the fact that the government and private sector have made a large contribution towards attending to the problem. Although progress has been made, there are still many poor and unemployed people in South Africa. This is clear from the results of the labour force survey finalised in September 2006. This survey demonstrated that the labour market consisted of 29852000 persons aged between 15-65 years; of these, 12451000 persons were employed and 4275000 persons were unemployed in terms of the official definition, meaning that they were unemployed, but would take up work within two weeks after participation in the survey. A further 13126000 people 
were economically inactive, 16726000 found themselves in the labour force or economically active, and 3683000 people were discouraged work seekers (Statistics South Africa, 2006:24).

Discouraged work seekers are defined as those who say that they would like to work and are able to work, but do not make any attempt to find a job (Statistics South Africa, 2006:2). The question could be asked why these people are not even willing to try to find a job. What is keeping them from seeking work? A variety of reasons are possible, including a lack of emotional energy to look for a job, laziness, a lack of life skills, or it may even be that they or someone close to them draws an income in the form of a grant.

According to the Department of Social Development (2006:2), most people receiving disability and child support grants are not motivated to join the workforce. Because of this the Department of Social Development (2006) published a discussion document pertaining to the linking of social grant beneficiaries to poverty alleviation and economic activity. In this document it is estimated that $36 \%$ of the beneficiaries of disability grants have disabilities that do not necessarily render them unable to obtain gainful employment. It further mentions that over $65 \%$ of the caregivers receiving child support grants are single parents and $94 \%$ of them are African. More than $11 \%$ of the caregivers have never received any formal education, while $71,5 \%$ have undergone 1-11 years of education. Over $85 \%$ of these caregivers are unemployed (Department of Social Development, 2006:3-5). These statistics indicate that there are many people who could contribute to the economic growth of the country; they just need to be activated to do so by means of improving their skills levels and intrinsic motivation. It would thus seem that the Department of Social Development is aware of the fact that these people need to be empowered to take the leap to the next level, which is why they suggest that the potential productive population should be mobilised and empowered in order to enjoy the dignity of work. This empowerment should take the form of a holistic approach in that (1) sustainable development, the reduction of poverty and the enabling of individuals should be encouraged; (2) programmes should focus on the individual and be concerned with human capital development; and (3) the welfare caseload should be reduced through the development of skills and career development (Department of Social Development, 2006:6-7). This implies that programmes should not just pay attention to the creation of jobs, the traditional way of managing poverty, but also to helping people to be effective and motivated in order to make a success of their work. This means that their EQ needs to be improved.

It is not only the Department of Social Development that has identified the need for poverty reduction, the enabling of individuals and the development of human capital. Other departments in the South African government have also identified the need to create work opportunities and the development of life skills. One of the very successful programmes initiated is the Expanded Public Works Programme (EPWP). This programme was started to address the magnitude of South Africa's structural unemployment crisis. The government's strategy with this programme is to reduce unemployment through increasing economic growth (Philips, 2004:2). When analysing this programme, it is clear that its architects felt that it should be meaningful. It was felt that the programme should deliver a vital service of high quality, not only to contribute to the economic growth of the country, but also to uplift the people involved in the process. The participants should feel that they are also making a contribution towards the upliftment of the country. Evident from the fourth quarterly report of the EPWP (2006) is the realisation that the development of life skills is essential to the programme's success and that the focus should not primarily be on the creation of jobs. These 
life skills programmes could be made more effective with the inclusion of activities that focus on Goleman's (1998:318) five basic emotional and social competencies.

It is important to understand that poverty does not merely involve a need for work, clothes, food and housing (absolute poverty). Many poor people also experience what I like to call emotional poverty. This type of poverty is seen as a lack of, amongst other things, selfconfidence, self-reliance and a personal vision. Swanepoel and De Beer (1997:24) add to this by saying that people not only have concrete needs, but also abstract needs, referring to attributes such as self-reliance, happiness and human dignity.

Thus, in order to make a significant impact on absolute poverty, development needs to become more than economic development. It has to focus on the enrichment of human lives and on the empowerment of the individual, as well as the eradication of emotional poverty. People should be assisted with the development of their self-concept, motivation, social skills, self-awareness and self-regulation. This then implies that a financially successful person could be poor on an emotional level and could benefit from an improved EQ. In this article poor people are referred to as people from disadvantaged communities that are economically and emotionally poor. The eradication of this type of poverty could be realised through playing the empowerment game and through the utilisation of adventure programmes.

\section{ADVENTURE PROGRAMMES}

When the term adventure is used, people tend to think about activities in nature, a rush of adrenalin, the taking of physical risks and huge costs; river rafting, rock-climbing and wilderness expeditions are seen in the mind's eye. Adventure counselling does not necessarily include all of this. In the context of this article "adventure" denotes a way of doing and not necessarily what is done. With this understanding of the term in mind, any environment could be potentially adventurous, especially if it contains an element of surprise and involves activities that motivate participants to go beyond their normal limits. Seen in this way, even the environment of the poor person could be made adventurous. Participation implies adventure and leads to unique experiences and the discovery of new information relevant to the client's situation. Adventure further implies the taking of "risks" to bring the participant to the brink of success or failure; the participant might be simultaneously successful and/or unsuccessful. Risk forms the basis of adventure and isn't merely physical in nature, but also has an emotional component. Risk also includes perceived danger when the participant is in fact very safe, provided that the facilitator knows what he or she is doing. It is very important that a person participating in an adventure programme feels that it is emotionally safe to share his/her feelings with others in the group. Because of this focus on emotional risk and safety, adventure programmes are excellent tools for the development and improvement of EQ.

The next part of this paper will give a general outline of the approach in order to describe the basics of adventure-orientated programmes. The model of Project Adventure, a US-based organisation that has conducted this kind of work for the past 30 years, will be used.

\section{THE BASICS OF ADVENTURE-BASED DEVELOPMENTAL PROGRAMMES}

Miles and Priest (1990:1) show that adventure is an activity that takes place when someone enters the unknown. For the adventurer this could imply risk and even danger. These days it would seem that the aim of a person's normal daily routine is to minimise adventure and reduce risk in order to improve the prospects for success. People thus have a natural need to protect themselves against danger and risks at different levels of their existence (physical, financial, social, intellectual and spiritual). 
Seeing that people naturally try to avoid danger and risks, it would be a novel experience for most when they are placed in a situation of adventure. This removes the person from his/her state of homeostasis. In the process of restoring homeostasis, growth and development take place. It has to be mentioned that some people like to put themselves into situations where they will experience danger and uncertainty, but this is not the norm.

Adventure-based programmes make use of a group therapeutic model that utilises finely selected activities within the framework of experiential learning. A combination of these is then used to bring about change in the group and in the life of the individual participant. Many of the activities are also used in education and recreational programmes (Schoel \& Maizell, 2002:ix). The difference between adventure education (adventure-based programmes) and adventure recreation is that the former changes behaviour and positively influences a client's life. This change is brought about when the client is put in a situation where s/he experiences a measure of psychological and physical stress in order to grow. During this process participants are confronted with new ideas, emotions and interactions, which form part of the activities. Nadler (1993:60) sees the process used for the effective planning of the intervention as follows: "...the client experiences a state of disequilibrium by being placed in a novel setting and a cooperative environment while being presented with unique problem-solving situations that lead to feelings of accomplishment which are augmented by processing the experience which promotes generalization and transfer to future endeavours".

Adding to this, Schoel, Prouty and Radcliffe (1988:24-25) explain that a typical session will last between one and two hours, during which attention will be given to tasks (behaviourist perspective), thoughts (cognitive psychological perspective) and feelings (affective perspective). This thus constitutes a holistic approach towards the client's development. During this process the person will develop and/or improve his problem-solving skills, self-image, thoughts and levels of motivation for doing something about his/her state of poverty.

The Project Adventure $(2002: 5,8)$ programme is built on this holistic approach as well as three other basic concepts, namely challenge by choice, the full-value contract and the experiential learning process. Using this in an integrated way gives the facilitator a unique tool with which to help clients to develop and grow to their full potential.

\section{Challenge by choice}

The concept of challenge by choice seeks to place the poor person in a situation that is slightly uncomfortable in order for growth to take place. The adventure activities are aimed at creating a safe environment for the participant, but one that is marked by surprise, challenges and fun. In this context challenge by choice gives the participant the opportunity to try potentially difficult and sometimes "terrifying" activities in a caring environment of trust and support. The participant has the opportunity to stand back from the activity when it becomes too frightening or if s/he does not have enough self-confidence. The learner knows that at a later stage s/he will have the opportunity to try again and push personal limits even further. It is important for the learner to understand that trying and pushing oneself is more important than the end product. The last important idea to keep in mind is that the learner should understand that there should be respect for the ideas held and choices exercised by others in the group (Project Adventure, 2002:5).

This concept grants the learner the opportunity to make his/her own decisions regarding participation in an environment of support. During the process each individual has to be helped to identify and work on his/her own opportunities for growth. The group process is conducted 
in such a way that positive peer pressure is utilised to facilitate change. The full-value contract is used to facilitate and enforce this. The participants get the opportunity to develop selfconfidence in managing the peer group, feelings and emotions. The client develops a positive self-image and learns that the end result isn't always the indicator of success, but that it lies in the process of achieving the end result. It has been observed in practice that the EQ of the participant is enhanced during this process.

The fact that the client receives the opportunity to identify his/her own challenges and decides on how far s/he wants to push the boundaries to achieve the set challenges does not mean that $\mathrm{s} /$ he has the opportunity to cut him/herself off from the group on a physical or emotional level. It is expected of each group member to contribute and to participate in the process. This does indeed mean that the participant would, for example, only share on the emotional level what $\mathrm{s} /$ he perceives as comfortable and on the physical level s/he will help to safeguard the other participants during the activity. As the participant grows during the process and develops greater self-confidence, participation levels will increase.

\section{The full-value contract}

The full-value contract forms the second pillar of the Project Adventure programme. Not only does it form part of the unique spirit of adventure-based programmes, but it is also seen as a very important component of group work in general (Toseland \& Rivas, 1998:164; Zastrow, 2001:356). According to Project Adventure (2002:6), a good contract should focus on the following:

- Group members have to identify safe behaviour and respectful norms within which the group will function;

- All group members should commit themselves to those norms and behaviour;

- The members should take shared responsibility for the enforcement of the contract during the process of adventure-based counselling (ABC).

According to Schoel et al. (1988:95) and Gilles (1995:2-3), the full-value contract requires the following commitments:

- An agreement among group members to work together to achieve both the individual goals and the goals of the group that were identified at the initial stages of the process;

- An agreement to adhere to certain safety and group behaviour guidelines. It is important to realise that these guidelines should be discussed with the group and should be agreed upon by the group members;

- An agreement to give and receive honest feedback. This means that group members agree to confrontation when their behaviour does not match the identified goals and/or values and norms that were decided on at the outset. The confrontation must be conducted in a caring and respectful manner;

- An agreement to increase one's own awareness of devaluing or discounting behaviour directed at other group members. Group members must be made aware of how they react towards other members and change their behaviour, if necessary, so that it is acceptable within the group and facilitates the growth of group members.

Evident from the above is that the contract will help the facilitator to achieve optimal results in terms of the development of EQ and personal empowerment as it focuses on Goleman's (1998:318) five basic emotional and social competencies. 
The participants work together in the writing of the contract. This is done in the participants' own words and in their own unique way. The contract may be presented in a variety of ways, for example, with the use of a flag, pictures from magazines, or a poster. It is important to remember that the younger the group, the more concrete the contract should be. Additions to the contract are made on a continuous basis, which means that it should be kept close at hand.

It is important that group members take shared ownership of their emotional and physical safety. As the group members decide what is acceptable and unacceptable within the group, the group will be partly responsible for the control that is exercised during the group process. When group members become co-responsible for the enforcement of group norms, they are placed in a position of power where they are empowered to take control of their own situation. The researcher found that the facilitator should have total control at the beginning of the process. However, as the process develops, this control will be reduced and the group members will become more empowered to determine the group's focus. This will also facilitate the development of the inter- and intra-personal skills.

\section{Experiential learning process}

The last important concept to take note of is the use of the experiential learning model (Figure 1). According to Gass (1993:4), most experiential learning programmes are based on the belief that learning or behavioural change must focus on including a direct experience in the growth process. It has furthermore been said that, in order to change, there should be a form of experience that triggers the change. This means that the closer a learner could be placed to the origin of change, the higher the transmission of knowledge is likely to be. Experiential learning further instils a sense of ownership over what has been learned and this also contributes towards the transfer of learning (Luckner \& Nadler, 1997:3-4). This process could contribute to learning and behavioural change in poor people. The experiential learning process, as developed by David Kolb (Osland, Kolb \& Rubin, 2001:43) and used by Jamison (2007), will be used to explain how learning and empowerment could be facilitated.

The first part of the process in terms of experiential theory consists of performing an activity (Jamison, 2007). This constitutes the doing part of the process and the activity or game forms the concrete experience that is needed to set the process in motion.

The second phase of the process is termed observation and reflection (Burnard, 1993:9), or share and process (Jamison, 2007). During this first part of the reflection phase the participants have to share the results of the activity as well as the reactions of group members and their general observations publicly. This narrative of the experience grants participants the opportunity to remember what happened and to become aware of events that took place during the activity and which went by unnoticed.

During the next phase (3) the participants are asked to discuss the positive and enriching as well as negative and degrading behaviour that surfaced during the activity. They have to discuss, analyse and reflect in order to process their learning.

The second last phase (4) starts when the group members have to connect the experience to real-life examples. In this phase the participant has to start to identify where in the real world $\mathrm{s} /$ he has experienced the identified behaviour or results of the activity. The influence of this behaviour should be discussed so that generalisations may be made. This will then lead to the next phase of the experiential learning process. 
The last phase (5) of the process starts when one begins to plan on how to apply this newlyacquired knowledge in novel situations. The question put to members is how they think they could use this new knowledge in their day-to-day life. This is where the real transfer of learning takes place.

FIGURE 1

THE EXPERIENTIAL LEARNING MODEL

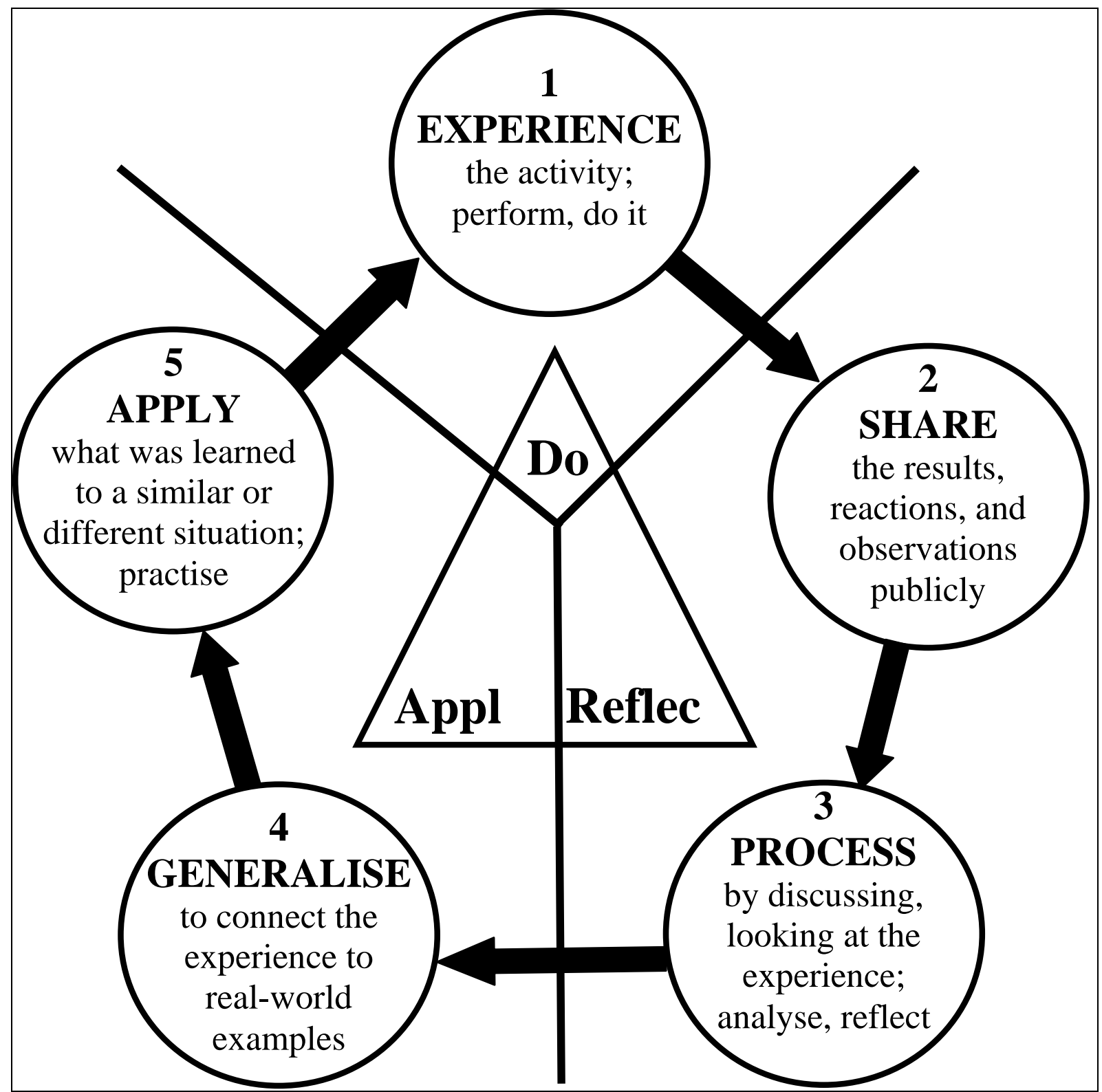

(Jamison, 2007)

The application of the experiential learning theory has the advantage that it uses simple adventure games and activities as well as other activities such as role-play, psychodrama and brainstorming to help participants see issues in their own lives differently (Burnard, 1993:1828; Schoel, et al., 1988:280-293). Games that are played and activities that are performed without an effective debriefing will mean nothing. Using this theory as a basis for debriefing encourages the poor person to look deeper into what has happened and to discover new solutions for old problems. These people are also helped to identify strengths that they were 
previously unaware of. These strengths do not only lie on the physical level but also on the emotional level. The poor are empowered to take charge of their personal circumstances and change their lives through the process of a positive learning experience.

\section{THE PROCESS OF ADVENTURE EMPOWERMENT}

As indicated in the introduction, this paper understands empowerment to be about helping poor community members to gain the power needed to make their own decisions and take control of their own lives by reducing the effect of social or personal blocks limiting their growth and by increasing their personal capacity and self-confidence.

In order to ensure that growth takes place, it is necessary for the facilitator to use his/her skills, knowledge and a positive attitude to create change. Luckner and Nadler (1997:28) are of the opinion that disequilibrium should be created in order to promote this change. This is done through adventurous activities and the use of the experiential learning process. When disequilibrium is created during the first and second phases of the above-mentioned process, the facilitator should be willing and ready to facilitate learning and change. This is where empowerment begins, as the clients are helped to gain the power of decision making and action over their own lives. The effect of social or personal blocks is reduced and personal capacity and self-confidence are increased (Payne, 2005:295).

Before learning really takes place, the comfort zones of the participants ought to be challenged. As the disequilibrium increases they will become aware of different, and in certain instances uncomfortable, feelings. This is what Luckner and Nadler (1997:29) call working at the edge. This is where the realm of possibilities is to be found and constitutes the point at which new territory can be explored. The next part will deal with what happens before success is attained, how to facilitate this and what the basic components of this so-called edgework are.

\section{WHAT HAPPENS AT THE EDGE?}

As people get closer to the unknown, their sense of disequilibrium increases and they start to experience uncertainty. Their feelings intensify; they may become fearful, anxious, confused, excited, or feel alone. Their physical symptoms change: palms perspire, hearts race and respiration quickens. Their internal conversation will also start to get louder; they will start saying to themselves things like: "I can't do this", "I'll fail", and "I must do this perfectly" (Luckner \& Nadler, 1997:29). The person is now at the so-called "edge" and has to make a decision: "Do I go on and hopefully attain success or do I retreat to a safe and comfortable environment without the exhilarating feeling of success?"

This usually happens during participation in the activity, i.e. phase 1 of the experiential learning process. I agree with Luckner and Nadler (1997:30) when they say that a wealth of valuable information gets lost if the facilitator waits for phases 2 and 3 of the experiential learning process before processing what has happened. If the facilitator waits too long before processing the feelings experienced, this information may be lost. This means that a facilitator should be attentive to what is happening in the group during the activity and be prepared to stop the activity for a few minutes in order to examine the feelings, patterns, beliefs and conversations of the group.

\section{PROCESSING}

High-quality processing is needed to increase the impact of the activity. The facilitator is to attempt to slow down or freeze the moments before the success or the retreat, so that individual thoughts, feelings and actions that make up their strengths and/or weaknesses become 
conscious and both internally and externally communicated (Luckner \& Nadler, 1997:31). The person should become emotionally aware of his/her inner self and what happens to other people, as this also forms part of EQ development (Le Roux \& De Klerk, 2001:12). The facilitator must be aware of what happens just before a leap is taken towards success or back to a safe environment.

When processing, the first thing that participants should be made aware of is what happened just before the decision for progress or retreat was made. How did they personally sabotage or aid their efforts? Next, attention is given to the level of responsibility. They have to own their patterns of conversation, feelings and actions, and they should also identify their own typical responses. The participants will then have to be motivated to experiment with new behaviours and strategies. Finally, with generalisation and transference, the participants can predict how they will respond when they encounter new edges at home or at work (Luckner \& Nadler, 1997:32-35).

In order to be effective in processing, the facilitator should be aware of the edge components. These are the things that one would make the group aware of during the processing and eventually alter or refine in order to assist group members in becoming more empowered beings.

\section{EDGE COMPONENTS}

It is important to recognise that many of the edge components that will be discussed overlap and influence each other. For the purposes of this discussion defences and typical patterns, feelings, physiology, beliefs, conversation, support and metaphors will be discussed separately (Luckner \& Nadler, 1997:36-44). The facilitator should note that these components contribute towards the development of a person's self-concept, one of the overall aims of adventure-based work (Schoel et al., 1988:12), and thus also to the emotional empowerment of the poor person.

\section{Defences and typical patterns}

People use different defence mechanisms to protect themselves against anxiety and fear of hurt and rejection. Zastrow (2001:136) mentions that a defence mechanism is a psychological attempt at avoiding or escaping painful conditions such as anxiety, frustration, hurt and guilt. He furthermore states that an individual's defence mechanisms are usually activated when s/he faces information that conflicts with his/her self-image. Defence mechanisms preserve the selfconcept and self-esteem and soften the blows of failure, deprivation or guilt. Some of these defence mechanisms include rationalisation, projection, denial, fantasy and isolation.

A participant feeling anxious about what ensued during an activity could thus start to employ a defence mechanism to protect him/herself from feeling inadequate. In many cases these defence mechanisms become part of the person's being and s/he isn't always even aware of what s/he is doing. The facilitator should make the group member aware of this behaviour and encourage him/her to experiment with new behaviour and more productive patterns.

\section{Feelings}

Deprived people also have feelings. According to Le Roux and De Klerk (2001:18), a feeling is an internal physical reaction to something you experience. The stimulus can be something you perceive through your senses and which you then interpret. Many people have learned not to feel and cannot manage their feelings, sometimes just tolerating uncomfortable, unfamiliar and negative feelings (Luckner \& Nadler, 1997:36). 
The greater the disequilibrium becomes during the activity, the more these feelings will intensify. In order to be able to manage these feelings, it is important to be aware of them and to take responsibility for them. Being able to manage feelings in a proper, uplifting manner is one of the indications of a higher EQ, as this demonstrates a deeper emotional awareness (Le Roux \& De Klerk, 2001:10).

\section{Physiology}

Specific physical symptoms may be associated with a particular feeling of discomfort. These symptoms could also be seen as internal clues such as a racing heartbeat, perspiration, a flushed face, a hollow feeling in the stomach, muscle contractions, and cold hands and feet (Le Roux \& De Klerk, 2001:22; Luckner \& Nadler, 1997:38).

If participants are aware of these physical symptoms and what they represent with regard to feelings, they can be helped to go beyond these roadblocks and develop new strategies for coping with these feelings. When the facilitator helps participants to identify the named physical symptoms and connect these with their feelings, it could become easier for them to continue and make one or another breakthrough. It could be helpful to explain a few stress management techniques to them such as improving the posture, breathing and positive self-talk (Davidson, 1999:235, 264, 279).

\section{Beliefs}

Beliefs usually start to develop very early in a person's life. People receive feedback from others with regard to what they are doing or not doing. Long-term inspirational or degrading feedback leads to the formation of a personal belief. This gives a person a "map" according to which s/he will behave. These beliefs will not feel good to the individual and could be selflimiting. Some of these core beliefs may include: "Something is wrong with me", "I can't", "I'm stupid" and "I don't know" (Luckner \& Nadler, 1997:39).

It would be the task of the facilitator to help the participant and the group to identify these selflimiting beliefs as this could hamper a breakthrough to the next level. It would be important to acknowledge personal achievements as well as to motivate the group to be receptive, encouraging and supportive to the individual. Breaking this self-limiting behaviour will contribute to the empowerment of group members.

\section{Conversation}

The beliefs that a person holds about him/herself are supported by his/her inner conversations. One will have an inner dialogue with oneself, thus sustaining the "scripts" created for oneself. One such script could be that s/he is not sufficiently intelligent to make big decisions and thus no decision is made. These conversations are used to plan, confirm or refute the map that s/he has about him/herself (Luckner \& Nadler, 1997:40).

As indicated previously, the facilitator will help the group members to become aware of their inner conversations and then focus their efforts on changing this to positive self-talk.

\section{Support}

Luckner and Nadler (1997:41) mention that a person's actions and choices are usually viewed as serving a positive purpose for them. Most people will choose a support that is either selfnurturing, or self-protective, or both. Qualities of these support systems include: (a) consistency, (b) security, (c) safety, (d) tension relief, (e) nourishment, (f) trustworthiness, and $(\mathrm{g})$ encouragement. In the light of this, a person may depend on things like drugs, food, work, a 
particular relationship, or a group to provide support. Personal experience has shown that many people have difficulty in directly asking for support and/or help.

Participants in an experiential activity could be helped to explore the type of support structures they have used in the past and to experiment with new, constructive ways of requesting and getting support from the group. In this process they learn to identify and use resources while at the edge. When confronted with other edge situations they will be prepared to ask for and make use of other, more constructive forms of support.

\section{Metaphors}

"I am on top of the world" and "I can see light at the end of the tunnel" are examples of metaphors. As seen from these examples, metaphors are very effective in communicating experiences. They constitute ideas, objects or descriptions that are identical in form and structure - but not necessarily in composition or function - to other ideas, objects or descriptions. The creation of metaphors is a natural and sometimes unconscious process that human beings employ in thinking and communicating. Metaphors can also be used to create patterns that connect the learning experience with the office, school or home environment (Luckner \& Nadler, 1997:42; Priest \& Gass, 1997:210).

The facilitator should assist the group in the formation of their own metaphors. They should be helped to connect their learning to other areas of life such as work and school. As they start to develop their own metaphors, it becomes easier to reconnect specific learning that has taken place at a later stage. The group could be asked to form their own "pictures" of what is happening at that stage. These "pictures" could be confirmed or changed at a later stage, whatever is applicable.

As seen in the foregoing discussion, it is necessary for the facilitator to make group members aware of their defences, feelings, physical changes, beliefs, communication, support and metaphors. Being aware of these will lead to an improved self-awareness that could contribute to a higher EQ. As a high EQ is seen as a contributing factor to personal success, attention will briefly be given to this phenomenon.

\section{DEVELOPING EMOTIONAL INTELLIGENCE AS PART OF THE EMPOWERMENT PROCESS}

Emotional intelligence is a relatively new and growing area of behavioural investigation, with researchers working hard towards understanding the nature of this construct. There is a great diversity of theories and definitions of EQ, which can be problematic in scientific study (Zeidler, Matthews, Roberts \& MacCann, 2003:69-70). As this paper does not constitute an evaluation of different theories, the theory of Mayer and Salovey will be used as a basis for discussion. Mayer and Salovey (1997:10) regard EQ as the ability to perceive accurately, appraise and express emotion; the ability to access and/or generate feelings when they facilitate thought; the ability to understand emotion and emotional knowledge; and the ability to regulate emotions to promote emotional and intellectual growth. From this definition it is evident that EQ is comprised of cognitive and emotional features.

Goleman (1998:317) accepted and refined the theory of Mayer and Salovey. He defined EQ within the workplace as the capacity for recognising one's own feelings and those of others, for motivating oneself, and for the effective management of emotions in one's relationships and in oneself. Three important elements of EQ emerge from this. They are the recognition of feelings, personal motivation and the management of emotions in relationships. 
Using the above definition, Goleman (1998:318) identified five basic emotional and social competencies. They are:

- Self-awareness - Knowing what you feel at any specific moment, and using that to guide decision-making as well as having a realistic assessment of your own abilities and a wellgrounded sense of self-confidence;

- Self-regulation - Handling emotions so that they facilitate and do not interfere with the task at hand; being conscientious and delaying gratification to pursue goals and recovering well from emotional distress;

- Motivation - Using your preferences to move and guide you towards your goals, to help you to initiate and strive for improvement and to persevere in the face of setbacks and frustrations;

- Empathy - Sensing what people are feeling, being able to take their perspective and cultivating rapport and harmonising with a diverse set of people;

- Social skills - Handling emotions in relationships well and accurately; reading social situations and networks; integrating smoothly; and using these skills to persuade and lead, negotiate and settle disputes for cooperation and teamwork.

With respect to the process of adventure empowerment and what should be achieved in this process, these basic emotional and social competencies will be developed. By using the experiential learning process and focusing on the edge components described, the facilitator will help participants to grow and develop their EQ. During this process their emotional poverty will be reduced and chances are good that they will become empowered to work on their material needs.

The question may be asked if there is a difference between EQ and emotional competencies. Blom (2000:54) is of the opinion that EQ shows the potential capacity that the individual has in terms of certain components consisting of specific knowledge, ability and skills in terms of emotional aspects. On the other hand, emotional competence shows the emotional competency of a person in terms of his/her ability to use his/her knowledge, ability and skills in this regard. A person that is emotionally capable has learned and is using emotions and emotional content. The conclusion is thus made that EQ can be learned and is thus something that can be changed. This supports the idea that adventure empowerment, which employs experiential learning, could be used in order to teach people to improve their EQ.

From the above definitions and the basic competencies defined by Goleman, it is apparent that EQ affects many aspects of an individual's mental and physical wellbeing. A high EQ will also facilitate the ability to get along with other people, to make sensible life choices, and to succeed in school, one's career and community life.

According to Abramovitz (2001:14), studies have shown that programmes aimed at the prevention of violence, teen smoking, drug abuse, pregnancy and school drop-out are most effective when they address the elements of EQ. Experts are also of the opinion that increased EQ can help to avoid both short-term injury risks and long-term illnesses such as heart disease, liver disease and certain cancers. These hazards are often a result of substance abuse and other dangerous lifestyle choices that go hand-in-hand with out-of-control emotional stress (Abramovitz, 2001:14). The opinion is held that the success of prevention programmes related to HIV and Aids could also be enhanced if EQ is improved. 
The EQ development of the clients of social workers (individuals, groups and communities) could thus exercise a positive effect on them as they sometimes suffer from problems pertaining to violence, drug abuse, low motivation and uncontrollable emotions.

In order to empower the poor, life-skills programmes should thus be promoted which, amongst others, focus on the development of adaptability; inter-personal and intra-personal skills; how to function effectively within a group; and skills related to the ability to influence others, in other words, the development of EQ (Ebersöhn \& Eloff, 2003:46-48). This can be done effectively with the use of experiential learning that uses adventure-based activities as described above.

\section{CONCLUSION}

The use of experiential learning and adventure-based activities to teach people new skills is not a new concept. Some of the cornerstones of adventure-based work, such as the use of a contract in a therapeutic setting, are also not new. In order to have an adventure experience, participants do not need a rush of adrenalin: they need an environment where they can learn new and exciting behaviour with the help of motivating and caring group members and a well-trained facilitator.

The focus of adventure empowerment falls on the identification and mobilisation of the inner potential of every person. People are motivated to take control of their lives and realise their potential and power. Furthermore, it focuses on the expansion of positive life values such as integrity, respect, love and loyalty. People experiencing difficult circumstances are encouraged to make choices so as to direct their lives within a framework of positive values.

An important principle of therapeutic adventure work is to motivate participants to do things that they would not normally do. They must leave the "safe" world to which they are accustomed for a new challenge. In this way unique outcomes are generated and people grow. This then leads to the empowerment of participants so that they can adapt more successfully to their environment and in so doing become well-adjusted, well-motivated citizens, that is, people who could successfully carry the burden of creating a better South Africa and reducing their own economic and emotional poverty.

Lastly, the effectiveness of the use of adventure to increase the EQ of poor people has not yet been verified in a scientifically accountable manner in the South African context. What is reflected upon in this article has been drawn mainly from personal experience, and from the feedback received from other practitioners and the available literature. There is, however, a need for in-depth longitudinal empirical research that will provide concrete scientific data to support the claims made in this article.

\section{REFERENCES}

ABRAMOVITZ, M. 2001. What's your emotional IQ? Current Health, 2:28(4):13-16.

BLOM, B. 2000. 'n Gestaltspelterapiehulpprogram in maatskaplike werk vir juniorprimêre skoolkinders se emosionele intelligensie. Bloemfontein: University of the Free State. (Unpublished $\mathrm{PhD}$ Thesis)

BURNARD, P. 1993. Teaching interpersonal skills. London: Chapman \& Hall.

DAVIDSON, J. 1999. The complete idiot's guide to managing stress. New York: Alpha Books. 
DEPARTMENT OF SOCIAL DEVELOPMENT. 2006. Discussion document. linking social grants beneficiaries to poverty alleviation and economic activity. Pretoria: South African Government.

EBERSÖHN, L. \& ELOFF, I. 2003. Life skills \& assets. Pretoria: Van Schaik.

EXPANDED PUBLIC WORKS PROGRAMME. 2006. Fourth quarterly report - year 2. Pretoria: South African Government.

GASS, M.A. 1993. Adventure therapy: therapeutic applications of adventure programmes. Dubuque: Kendall/Hunt..

GILLES, H.L. 1995. ABC workshop manual. Dubuque, IL: Kendall/Hunt.

GOLEMAN, D. 1998. Working with emotional intelligence. New York: Bantam.

JAMISON, K. 2007. Presentation on curriculum and learning, adapted from national 4-h curriculum handbook, 1992. Available: http://njaes.rutgers.edu/learnbydoing/weblinks.html. [Date of retrieval: 07/08/2007].

LE ROUX, R. \& DE KLERK, R. 2001. Emotional intelligence workbook. Cape Town: Human \& Rousseau.

LUCKNER, J.L. \& NADLER, R. S. 1997. Processing the experience: strategies to enhance and generalize learning. Dubuque: Kendall/ Hunt.

MAYER, J.D. \& SALOVEY, P. 1997. What is emotional intelligence? In: SALOVEY, P. \& SLUYTER, D. (eds) Emotional development and emotional intelligence: educational implications. New York: Basic Books.

MILES, J.C. \& PRIEST, S. 1990. Adventure education. Philadelphia: Venture Publishing.

NADLER, R.S. 1993. Therapeutic process of change. In: GASS, M.A. (ed) Adventure therapy: therapeutic applications of adventure programmes. Dubuque, IA: Kendall/Hunt.

OSLAND, J.S., KOLB, D.A. \& RUBIN, I.M. 2001. Organizational behaviour. An experiential approach $\left(7^{\text {th }}\right.$ ed). Upper Saddle River, NJ: Prentice-Hall.

PAYNE, M. 2005. Modern social work theory ( $3^{\text {rd }}$ ed). New York: Palgrave MacMillan.

PHILIPS, S. 2004. Overcoming underdevelopment in South Africa's second economy. Pretoria: National Department of Public Works.

POVERTY AND INEQUALITY INSTITUTE. 2007. The measurement of poverty in South Africa project: key issues. Johannesburg: Studies in Poverty and Inequality Institute.

PRIEST, S. \& GASS, M. 1997. Effective leadership in adventure programming. Champaign, IL: Human Kinetics.

PROJECT ADVENTURE. 2002. Adventure programming training manual. Beverly: Project Adventure.

REYNEKE, R.P. 2000. 'n Narratiewe maatskaplikewerkbenadering vir gemeenskapsbemagtiging. Bloemfontein: University of the Free State. (Unpublished PhD Thesis)

SCHOEL, J. \& MAIZELL, R. 2002. Exploring islands of healing: new perspectives on adventure-based counselling. Beverly: Project Adventure. 
SCHOEL, J., PROUTY, D. \& RADCLIFFE, P. 1988. Islands of healing: a guide to adventure-based counselling. Beverly: Project Adventure.

STATISTICS SOUTH AFRICA. 2006. Labour force survey. statistical release P0210. Available: http://www.statssa.gov.za/publications/P0210/P0210March2006.pdf. [Date of retrieval: 23/01/2009].

SWANEPOEL, H. \& DE BEER, F. 1997. Introduction to development studies. Johannesburg: Thomson.

TOSELAND, R.W. \& RIVAS, R.F. 1998. An introduction to group-work practice. Boston: Allyn \& Bacon.

ZASTROW, C. 2001. Social work with groups. Using the class as a group leadership laboratory $\left(5^{\text {th }}\right.$ ed $)$. Belmont: Brookes/Cole.

ZEIDLER, M., MATTHEWS, G., ROBERTS, R.D. \& MacCANN, C. 2003. Development of emotional intelligence: toward a multi-level investment model. Human Development, (46):6-96.

Dr Roelf Reyneke Department of Social Work, University of the Free State, Bloemfontein, South Africa. 